FY 2007

\title{
FINAL REPORT ON CONTROL ALGORITHM TO IMPROVE THE PARTIAL-LOAD EFFICIENCY OF SURFACE PM MACHINES WITH FRACTIONAL-SLOT CONCENTRATED WINDINGS
}

Prepared by:

Oak Ridge National Laboratory

Mitch Olszewski, Program Manager

Submitted to:

Energy Efficiency and Renewable Energy

FreedomCAR and Vehicle Technologies

Vehicle Systems Team

Susan A. Rogers, Technology Development Manager

April 2007 
NATIONAL LABORATORY

MANAGED BY UT-BATTELLE

FOR THE DEPARTMENT OF ENERGY

\section{FINAL REPORT ON CONTROL ALGORITHM TO IMPROVE THE PARTIAL-LOAD EFFICIENCY OF SURFACE PM MACHINES WITH FRACTIONAL-SLOT CONCENTRATED WINDINGS}

Patel B. Reddy

Prof. Thomas M. Jahns

University of Wisconsin-Madison

Publication Date: April 2007

Prepared by the

OAK RIDGE NATIONAL LABORATORY

Oak Ridge, Tennessee 37831 managed by

UT-BATTELLE, LLC

for the

U.S. DEPARTMENT OF ENERGY

Under contract DE-AC05-00OR22725 


\section{DOCUMENT AVAILABILITY}

Reports produced after January 1, 1996, are generally available free via the U.S. Department of Energy (DOE) Information Bridge:

Web site: http://www.osti.gov/bridge

Reports produced before January 1, 1996, may be purchased by members of the public from the following source:

National Technical Information Service

5285 Port Royal Road

Springfield, VA 22161

Telephone: 703-605-6000 (1-800-553-6847)

TDD: $703-487-4639$

Fax: 703-605-6900

E-mail: info@ ntis.fedworld.gov

Web site: http://www.ntis.gov/support/ordernowabout.htm

Reports are available to DOE employees, DOE contractors, Energy Technology Data Exchange (ETDE) representatives, and International Nuclear Information System (INIS) representatives from the following source:

Office of Scientific and Technical Information

P.O. Box 62

Oak Ridge, TN 37831

Telephone: 865-576-8401

Fax: 865-576-5728

E-mail: reports@osti.gov

Web site: http://www.osti.gov/contact.html

This report was prepared as an account of work sponsored by an agency of the United States Government. Neither the United States government nor any agency thereof, nor any of their employees, makes any warranty, express or implied, or assumes any legal liability or responsibility for the accuracy, completeness, or usefulness of any information, apparatus, product, or process disclosed, or represents that its use would not infringe privately owned rights. Reference herein to any specific commercial product, process, or service by trade name, trademark, manufacturer, or otherwise, does not necessarily constitute or imply its endorsement, recommendation, or favoring by the United States Government or any agency thereof. The views and opinions of authors expressed herein do not necessarily state or reflect those of the United States Government or any agency thereof. 


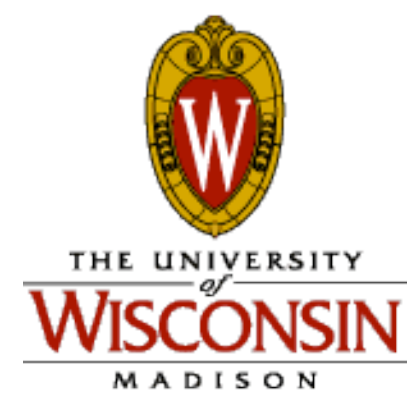

MEMO REPORT PREPARED FOR:

UT-Battelle / Oak Ridge National Laboratory

\title{
Final Report on Control Algorithm to Improve the Partial-Load Efficiency of Surface PM Machines with Fractional-Slot Concentrated Windings
}

\author{
Prepared by: \\ Patel B. Reddy \\ Prof. Thomas M. Jahns
}

Date:

January 15, 2007

Technical Supervisor: Dr. John McKeever

Oak Ridge National Laboratory

Oak Ridge, TN

T: (865) 946-1316

E: mckeeverjw@ornl.gov 


\section{Final Report on Control Algorithm to Improve the Partial-Load Efficiency of Surface PM Machines with Fractional-Slot Concentrated Windings}

\section{Introduction}

Surface permanent magnet (SPM) synchronous machines using fractional-slot concentrated windings are being investigated as candidates for high-performance traction machines for automotive electric propulsion systems. It has been shown analytically and experimentally that such designs can achieve very wide constant-power speed ratios (CPSR) [1,2]. This work has shown that machines of this type are capable of achieving very low cogging torque amplitudes as well as significantly increasing the machine power density [3-5] compared to SPM machines using conventional distributed windings. High efficiency can be achieved in this class of SPM machine by making special efforts to suppress the eddy-current losses in the magnets [6-8], accompanied by efforts to minimize the iron losses in the rotor and stator cores.

Considerable attention has traditionally been devoted to maximizing the full-load efficiency of traction machines at their rated operating points and along their maximum-power vs. speed envelopes for higher speeds [9,10]. For example, on-line control approaches have been presented for maximizing the full-load efficiency of PM synchronous machines, including the use of negative $d$-axis stator current to reduce the core losses $[11,12]$.

However, another important performance specification for electric traction applications is the machine's efficiency at partial loads. Partial-load efficiency is particularly important if the target traction application requires long periods of cruising operation at light loads that are signficantly lower than the maximum drive capabilities. While the design of the machine itself is clearly important, investigation has shown that this is a case where the choice of the control algorithm plays a critical role in determining the maximum partial-load efficiency that the machine actually achieves in the traction drive system. There is no evidence that this important topic has been addressed for this type of SPM machine by any other authors.

This topic takes on even greater significance for fractional-slot concentrated-winding SPM machine designs. In particular, maximizing the torque/power density of this class of SPM machines typically leads to machine designs with high numbers of poles. The resulting high electrical frequencies can easily result in high stator core losses unless special care is taken during the machine design process.

The purpose of this report is to discuss a modified vector control algorithm for a fractional-slot concentrated winding SPM machine that has been developed to maximize the machine's partialload efficiency over a wide range of operating conditions. For purposes of this discussion, a 55 $\mathrm{kW}$ (peak) SPM machine designed to meet requirements established in the US FreedomCar program [13] is used as the basis for demonstrating the proposed technique. A combination of closed-form analysis [14] and finite element analysis (FEA) is used during this investigation. 
TABle I: COMPARISON OF TRACTION Motor SPECIFICATION AND SPMI DESIgn ReSUltS

\begin{tabular}{|c|c|c|}
\hline Requirement & Target Specification & SPM1 Design \\
\hline Minimum top speed $[\mathrm{rpm}]$ & 10,000 & 10,000 \\
\hline Peak Power at $20 \%$ of max speed for $18 \mathrm{sec}$ and nominal voltage $[\mathrm{kW}]$ & 55 & 55 \\
\hline $\begin{array}{c}\text { Continuous power at } 20 \% \text { to } 100 \% \text { of maximum speed and nominal } \\
\text { voltage }[\mathrm{kW}]\end{array}$ & 30 & 30 \\
\hline Battery operating voltage $[\mathrm{Vdc}]$ & $\begin{array}{c}\text { Nominal: } 325 \\
\text { Range: } 200 \text { to } 450\end{array}$ & $\begin{array}{c}\text { Nominal: } 325 \\
\text { Range: } 200 \text { to } 450\end{array}$ \\
\hline Maximum current at motor [Arms] & 400 & 330 \\
\hline Characteristic current [Arms] & $<$ Max Current & 146.3 \\
\hline Efficiency at 10 to $100 \%$ of max speed rated power & $>93 \%$ & $93 \%$ \\
\hline Efficiency at 10 to $100 \%$ of max speed for $20 \%$ of rated torque & $>93 \%$ & See Figs 6,7 \\
\hline Torque pulsations -not to exceed at any speed [\% of peak torque] & $<5$ & 6.5 (From FEA) \\
\hline Peak power to weight ratio for active materials $[\mathrm{kW} / \mathrm{Kg}]$ & $>2.75$ & 3.44 \\
\hline Peak power to volume ratio for active materials [kW/liter] & $>12.5$ & 26.2 \\
\hline
\end{tabular}

TABle II. Summary of Key Dimensions and Parameters of the 36SLot/30pole SPM1 Machine Design

\begin{tabular}{|c|c|c|c|}
\hline Slot/Pole/Phase $(\mathrm{SPP})$ & $2 / 5$ & Total Mass $[\mathrm{kg}]$ & 16.3 \\
\hline Outer Diameter $[\mathrm{mm}]$ & 269 & Magnet Remanent Flux Density, $B_{r}[\mathrm{Tesla}]$ & $1.0 @ 140^{\circ} \mathrm{C}$ \\
\hline Active Length $[\mathrm{mm}]$ & 63.5 & Magnet relative permeability & 1.05 \\
\hline Air Gap Thickness [mm] & 1.5 & Magnet Thickness [mm] & 7.5 \\
\hline Total Length [mm] & 75.4 & Stator SeriesTurns/phase, $N_{s}[\mathrm{Turns}]$ & 48 \\
\hline Magnets Outer Radius [mm] & 99.6 & No. of Parallel Paths & 1 \\
\hline Rotor Outer Radius $[\mathrm{mm}]$ & 92.1 & Rated Current Density $\left[\mathrm{A} / \mathrm{mm}^{2}\right]$ & 6.7 \\
\hline Rotor Inner Radius $[\mathrm{mm}]$ & 82.1 & Peak Current [A rms] & 330 \\
\hline RMS PM flux linkage $[\mathrm{mWb}-\mathrm{rms}]$ & 26.3 & Peak Current Density $\left[\mathrm{A} / \mathrm{mm}^{2}\right]$ & 15.4 \\
\hline Phase Inductance $[\mu \mathrm{H}]$ & 179.5 & Rated Armature Losses $[\mathrm{W}]$ & 734 \\
\hline Char. Current, $I_{c h}[\mathrm{~A} \mathrm{rms}]$ & 146.3 & Rated Core Losses $[\mathrm{W}]$ & 1911 \\
\hline Rated Current, $I_{R}[\mathrm{~A} \mathrm{rms}]$ & 144 & Slot Fill Factor $[\mathrm{pu}]$ & 0.7 \\
\hline FW_index $\left(I_{c h} / I_{R}\right)$ & 1.02 & Rotor Active Volume $\left[\mathrm{m}^{3}\right]$ & 0.00198 \\
\hline Copper Mass $[\mathrm{kg}]$ & 4.6 & Continuous Air Gap Shear Stress $[\mathrm{psi}]$ & 5.8 \\
\hline Iron Mass $[\mathrm{kg}]$ & 9.7 & “ “ $[\mathrm{kPa}]$ & 40 \\
\hline Magnet Mass $[\mathrm{kg}]$ & 2 & LCM (S,2P) & 180 \\
\hline
\end{tabular}

\section{Summary of $55 \mathrm{~kW}$ SPM Machine Design}

A 36slot/30pole fractional-slot concentrated winding SPM machine using sintered magnets has been designed to meet the required performance specifications summarized in Table I. A cross-section of the basic stator-rotor repeating unit for this machine (referred to henceforth as $S P M 1)$ is presented in Fig. 1 and several key dimensions and parameters of this machine are summarized in Table II. The attractive performance metrics predicted for this machine design are summarized in the last column of Table I for convenient comparison with the specifications. Two-dimensional FEA has been used to build confidence in these calculated results. 


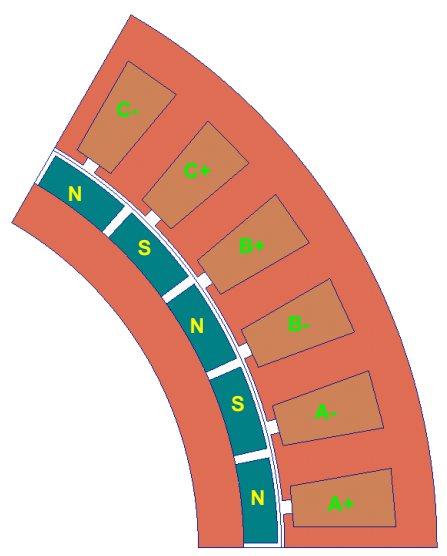

Figure 1. Cross-section of the basic repeating unit of the $55 \mathrm{~kW}$ (peak) 36slot $/ 30$ pole $(2 / 5 \mathrm{~s} / \mathrm{p} / \mathrm{ph})$ SPMI machine design

The stator structure is assumed to be segmented in order to achieve a high slot copper fill factor of 0.7 (defined as the ratio of the copper cross-sectional area to the total slot area) [15], making it possible to increase the machine's power density by reducing its copper losses. In addition, each magnet pole is segmented into 5 pieces in order to minimize the eddy-current losses in the magnets caused by the spatial harmonic components in the airgap magnetic field [6].

\section{Core Loss Model}

Several authors have presented analytical models for calculating the core losses in ac electrical machines. The core losses for this investigation have been calculated using the model presented in [16]. This model is defined in terms of machine dimensions and material properties, and its prediction accuracy characteristics are quite good, making it an appealing choice for this machine design optimization exercise. The interested reader is directed to the original reference [16] for more details about this model and its derivation which will not be presented here.

The peak air gap flux density as well as the peak stator-tooth and stator-yoke flux densities have been calculated analytically for the SPM1 machine using a model for fractional-slot concentrated-winding machines that has been presented in a previous paper [14]. The results of this model for the SPMI machine have been verified using FEA as will be discussed in Section V. The core loss coefficients used in the calculations are dependent on the lamination material and thickness. The coefficient values used for this analysis lie in the middle of the typical ranges presented in [16] and are identified in the following discussion.

\section{A. Tooth Eddy-Current Loss Model}

The stator tooth eddy-current losses per unit volume can be calculated using the following equations:

$$
P_{e t}=\frac{4 m}{\pi^{2}} q k_{q} k_{l} k_{e}\left(\omega_{e} B_{t h}\right)^{2} \quad\left[\mathrm{~W} / \mathrm{m}^{3}\right]
$$


where $P_{e t}$ is the stator tooth eddy-current power loss per unit volume [W/m $\left.\mathrm{m}^{3}\right], m$ is the number of phases, $k_{e}$ is the eddy current constant (depends on the lamination material; typically 0.04-0.07 [16]), $k_{q}$ is the motor geometry correction factor (depends on the motor geometry; see [16] for details), $k_{l}$ is the correction factor to account for the contribution of the circumferential loss component (see [16] for details), $\omega_{e}$ is the electrical angular velocity [ $\left.\mathrm{rad} / \mathrm{sec}\right], q$ is the number of slots/pole/phase, and $B_{t h}$ is the peak magnetic flux density in the tooth [Tesla]. The value of $B_{t h}$ can be calculated as follows:

$$
B_{t h}=\frac{W_{t}+W_{s}}{W_{t}} \hat{B}_{g} \quad \text { [Tesla] }
$$

where $W_{t}$ is the tooth width [m], $W_{s}$ is the slot width [m], and $\hat{B}_{g}$ is the peak air gap magnetic flux density [Tesla]. The value of $\hat{B}_{g}$ can be calculated as follows:

$$
\hat{B_{g}} \approx \frac{\left.V_{a g}\right)_{r m s} p}{\sqrt{2} R_{S} l_{\text {eff }} N_{\text {phase }} K_{w 1} \omega_{e}} \quad \text { [Tesla] }
$$

where $\left.V_{a g}\right)_{r m s}$ is the airgap supply voltage [V rms], $p$ is the number of machine pole pairs, $N_{\text {phase }}$ is the number of series turns/phase, $K_{w l}$ is the synchronous winding factor, $R_{S}$ is the airgap radius $[\mathrm{m}]$, and $l_{\text {eff }}$ is the active stack length [m].

It should be observed that the calculation of the peak air gap magnetic flux density $\hat{B}_{g}$ in (3) above (and, hence, the values of the peak stator-tooth and stator-yoke magnetic flux densities) are based on a key assumption of sinusoidal flux density distributions. This key approximation will be justified using FEA results presented later in Section V.

\section{B. Yoke Eddy-Current Loss Model}

The stator yoke eddy-current losses/unit volume can be calculated using the following equation:

$$
P_{e y}=\frac{1}{\alpha} \frac{8}{\pi^{2}} k_{e} k_{r}\left(\omega_{e} B_{y}\right)^{2} \quad\left[\mathrm{~W} / \mathrm{m}^{3}\right]
$$

where $P_{e y}$ is the stator yoke eddy-current power loss per unit volume $\left[\mathrm{W} / \mathrm{m}^{3}\right], k_{r}$ is a constant (defined below), $\alpha$ is the magnet width-to-arc-length ratio (defined below), and $B_{y}$ is the peak magnetic flux density in the stator yoke [Tesla]. The values of $\alpha, k_{r}$, and $B_{y}$ can be calculated as follows:

$$
\alpha=\frac{W_{m}}{\frac{2 \pi R_{s}}{2 p}} \quad k_{r}=1+\frac{8 k_{q} d_{y}{ }^{2}}{27 \alpha q \lambda_{2}{ }^{2}} \quad B_{y}=\frac{W_{m}}{2 d_{y}} \hat{B}_{g} \quad[\mathrm{~T}]
$$

where $d_{y}$ is the stator yoke thickness [m], $W_{m}$ is the magnet width [m], and $\lambda_{2}$ is the projected slot pitch at the middle of the stator yoke $[\mathrm{m}]$.

\section{Hysteresis Loss Model}

The stator-tooth and stator-yoke hysteresis losses per unit volume can be calculated using the following equations: 


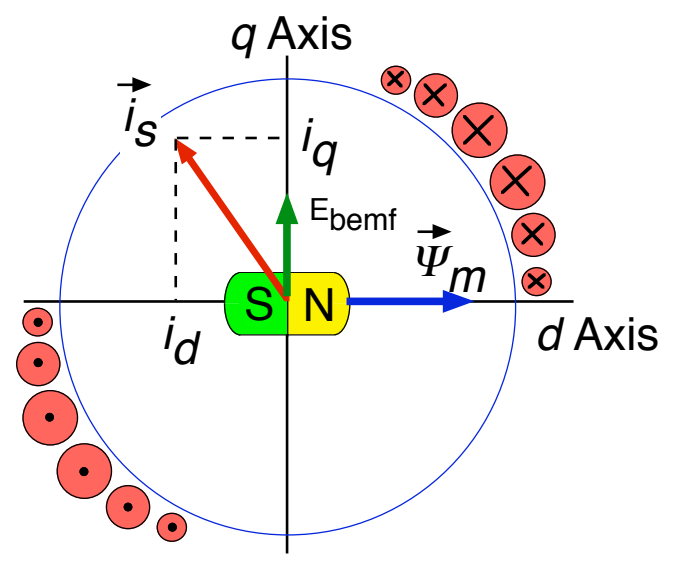

Fig. 2: Cross section of two-pole machine illustrating a stator current vector and is decomposition into $d$ - and $q$-axis components in order to achieve vector control of an SPM machine.

$$
\begin{array}{ll}
P_{h t}=k_{h} \omega_{e} B_{t h}{ }^{\beta} & {\left[\mathrm{W} / \mathrm{m}^{3}\right]} \\
P_{h y}=k_{h} \omega_{e} B_{y}{ }^{\beta} & {\left[\mathrm{W} / \mathrm{m}^{3}\right]}
\end{array}
$$

where $P_{h t}$ is the stator-tooth hysteresis power loss per unit volume [W/m $\left./ \mathrm{m}^{3}\right], P_{h y}$ is the stator yoke hysteresis power loss per unit volume $\left[\mathrm{W} / \mathrm{m}^{3}\right], k_{h}$ is the hysteresis loss constant (depends on the lamination material; typically 40-55 [16]), and $\beta$ is the Steinmetz constant (depends on the lamination material; typically 1.8-2.2 [16]).

\section{Total Iron Loss Model}

Using the results presented above, the total iron losses can be calculated as follows:

$$
P_{\text {iron }}=\left(P_{e t}+P_{h t}\right) V_{t}+\left(P_{e y}+P_{h y}\right)_{y} \quad[\mathrm{~W}]
$$

where $P_{\text {iron }}$ is the total iron losses in the machine [W], $V_{t}$ is the total stator-tooth volume $\left[\mathrm{m}^{3}\right]$, and $V_{y}$ is the total stator yoke volume $\left[\mathrm{m}^{3}\right]$.

\section{Enhanced Partial Load Efficiency Control Algorithm}

High-performance torque control in SPM machines can be achieved using current-regulated vector control. According to this technique, the amplitudes of the instantaneous currents in the three stator phases are controlled so that their combined effect can be represented on a crosssection of the machine as a vector that has an amplitude (i.e., length) and angle. A simple representation of this concept for a 2-phase ac machine is provided in Fig. 2 that illustrates a current vector $\vec{i}_{s}$. Newcomers to this concept are referred elsewhere for more details [17].

According to the basic concept of vector control, the amount of torque that is produced by an SPM machine is determined by both the amplitude of the current vector $\vec{i}_{s}$ and, very importantly, by its angle with respect to the orientation of the rotor magnets. In Fig. 2, the rotor magnet orientation is represented by the magnet flux linkage vector $\vec{\Psi}_{m}$ aligned with the north pole of the 


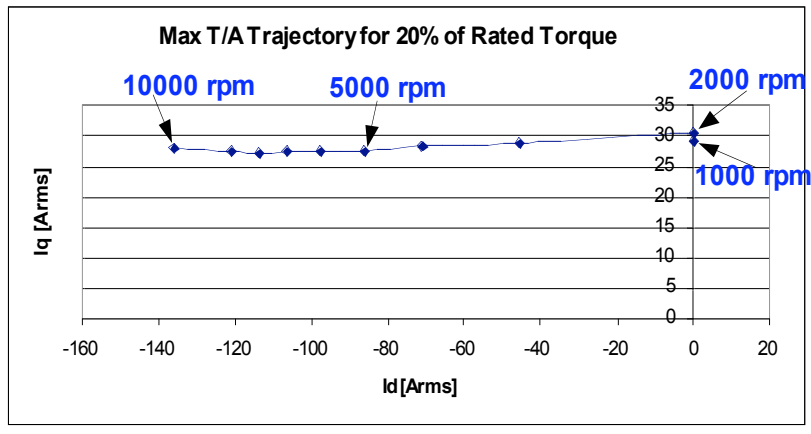

Fig. 3: Maximum Torque/Amp current vector trajectory for $S P M 1$ machine at $20 \%$ of rated torque

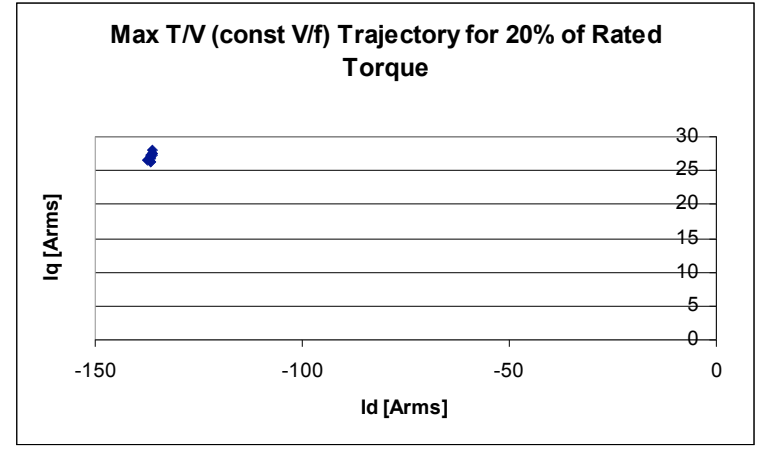

Fig. 4: Maximum Torque/Volt current vector trajectory for $S P M 1$ machine at $20 \%$ of rated torque

rotor magnets. A two-axis plane can be uniquely defined that is locked to the rotor's instantaneous angular position at every time instant so that the orientation of $\vec{\Psi}_{m}$ is defined to be the direct or $d$-axis, and an orthogonal axis is defined as the quadrature or $q$-axis. As a result, any current vector such as $\vec{i}_{s}$ in Fig. 2 can be uniquely decomposed into an $i_{d}$ component along with the $d$-axis and an $i_{q}$ component aligned with the $q$-axis. The torque and the terminal voltage developed by the SPM machine are determined by the values of $i_{d}$ and $i_{q}$, so controlling these two orthogonal current components provides the basis for controlling the torque production of the machine.

Conventional vector control algorithm for SPM machines is based on minimizing the stator copper losses by adjusting the stator current in the rotor-based $d q$ frame to achieve maximum torque-per-Amp $(\max T / A)$ operation $[9,10]$. Figure 3 shows the calculated current vector trajectory line for maximum torque/Amp operation of the SPM1 machine over a wide range of rotor speeds in the $i_{q}-i_{d}$ plane when delivering $20 \%$ of rated torque. According to this algorithm, the value of $i_{q}$ is essentially constant while $i_{d}$ is gradually increased (with negative polarity) as the speed is increased beyond the corner point value to accomplish the necessary flux weakening. Flux weakening is required at elevated speeds to counteract the effect of the magnet flux linkage $\vec{\Psi}_{m}$ sufficiently so that the terminal voltage of the machine at each speed will remain within the maximum limit set by the available source voltage.

It is useful to identify an alternative version of this vector control algorithm to minimize the machine's terminal voltage under all operating conditions by using as much negative $d$-axis current as available to accomplish this objective. The current vector trajectory for this maximum torque-per-Volt strategy is shown in Fig. 4 for the SPMI machine at $20 \%$ of rated torque, exhibiting very little motion over the full speed range. That is, the same current vector amplitude is applied at all speeds, adjusted so that its amplitude equals the rated continuous current value. This algorithm is referred to as maximum torque-per-Volt $(\max T / V)$.

This $\max T / V$ algorithm is useful for illustration purposes in this discussion because it has the special feature of minimizing the stator core loss by minimizing the stator flux density at all speeds. However, its practical usefulness is very limited since this iron loss minimization is accomplished at the price of maximizing the copper loss. 


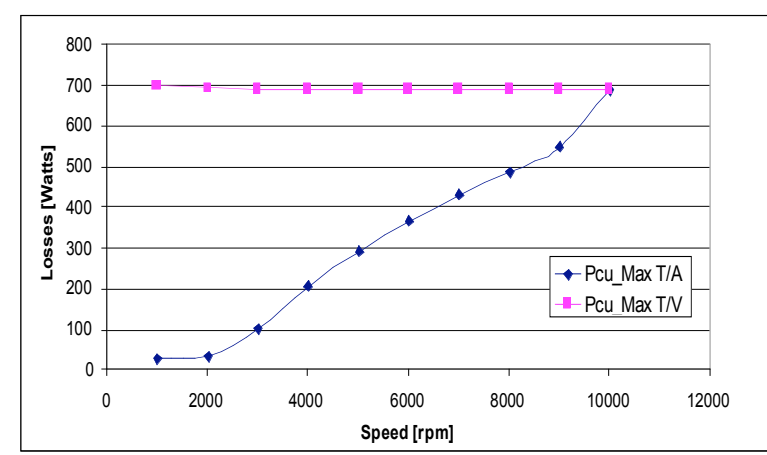

Fig. 5: Comparison of predicted copper losses for $20 \%$ of rated torque with $\max T / A$ and $\max T / V$ algorithms

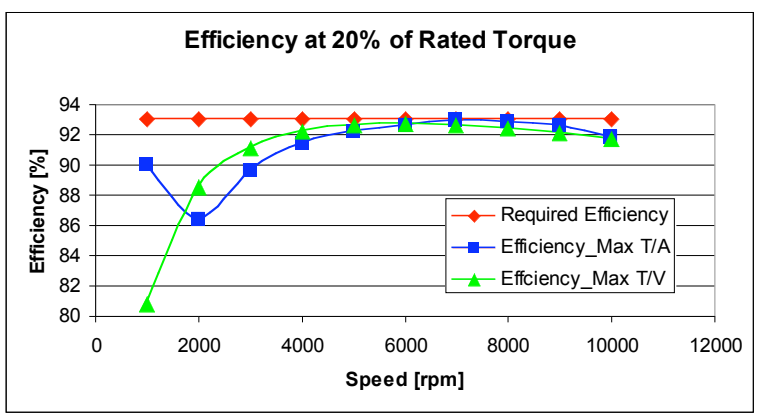

Fig. 7: Predicted efficiency of SPM1 machine at 20\% of rated torque for $\max T / A$ and $\max T / V$ algorithms, plus specified min. efficiency line.

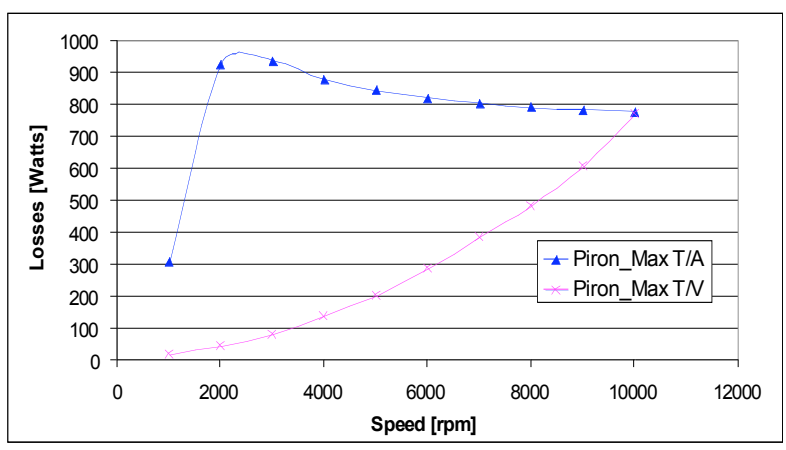

Fig. 6: Comparison of predicted iron losses for $20 \%$ of rated torque with $\max T / A$ and $\max T / V$ algorithms

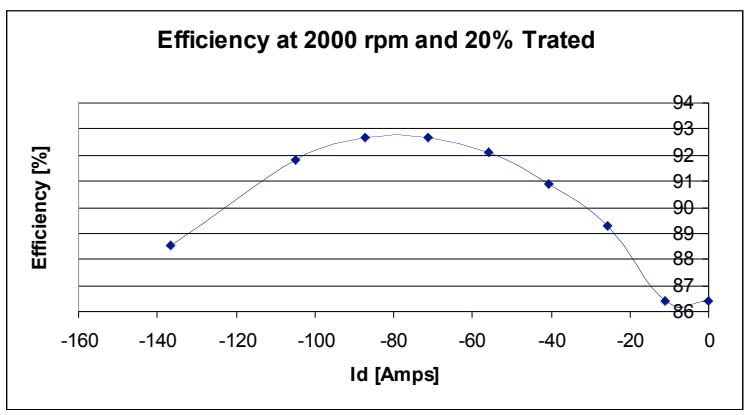

Fig. 8: Variation of $S P M 1$ efficiency at $2000 \mathrm{rpm}$ as a function of $i_{d}$ with $i_{q}$ adjusted to hold the torque constant at $20 \%$ of rated torque

Some valuable insights are also available by comparing the calculated loss components with each of these two vector control algorithms. Figure 5 confirms that the maximum torque-perAmp algorithm ( $\max T / A)$ delivers lower copper losses at all speeds below maximum speed (10 $\mathrm{krpm})$ compared to the maximum torque-per-Volt $(\max T / V)$ algorithm. On the other hand, Fig. 6 shows that the roles reverse for iron core losses [16], with the max $T / V$ algorithm achieving significantly lower core losses than the $\max T / A$ algorithm at all speeds below $10 \mathrm{krpm}$.

An important observation from this exercise is that the max $T / V$ algorithm tends to yield higher efficiency at speeds where the iron losses are dominant, while the $\max T / A$ algorithm tends to achieve higher efficiency at speeds where copper losses are dominant. Figure 7 confirms this observation by comparing the predicted efficiency of the SPM1 machine at $20 \%$ of rated torque for the two algorithms over a wide speed range. More specifically, Fig. 7 shows that the max $T / A$ algorithm is significantly better for minimizing the total machine losses at low speeds where the iron losses tend to be the lowest, but the $\max T / V$ algorithm demonstrates its superiority at higher speeds above approx. $2000 \mathrm{rpm}$ where iron losses are much higher. Unfortunately, Fig. 7 also shows that neither algorithm is capable of achieving the $93 \%$ efficiency target for the FreedomCar traction motor, with the largest deficiencies appearing at low speed. 


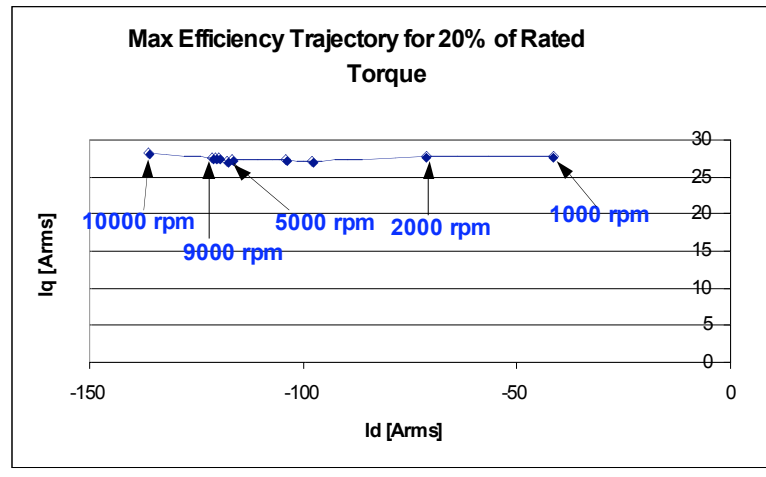

Fig. 9: Current vector trajectory for SPMI machine to deliver maximum partial-load efficiency at $20 \%$ of rated torque

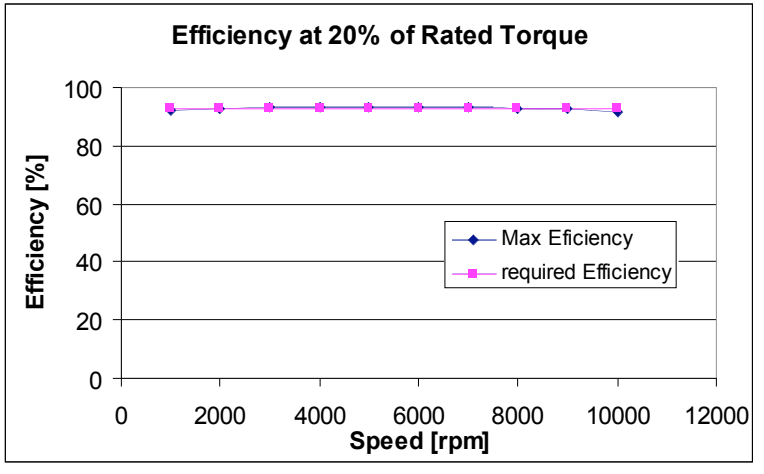

Fig. 10: Predicted efficiency of SPMI machine at $20 \%$ of rated torque for maximum partial-load efficiency, plus specified min. efficiency line

A critical observation at this stage is that the $\max T / A$ and $\max T / V$ algorithms represent two distinct extremes in the vector control spectrum. In between these two extremes are an infinite number of alternative formulations. Each candidate algorithm represents a different weighted blending of the two extremum algorithms, raising the possibility that a blended algorithm might perform better than either $\max T / A$ and $\max T / V$ alone.

Stated differently, an investigation was launched to determine whether there might be another combination of $I_{q}$ (which determines the resulting torque) and $I_{d}$ (used to adjust the flux level in the machine) that will lead to higher machine efficiency values than either the pure max $T / A$ or $\max T / V$ algorithms.

The results of this investigation have been very promising, indicating that the appropriate blend of the two algorithms can yield significant improvements in the machine efficiency, particularly at those speeds that exhibit the largest deficiencies in Fig. 7. As an example, Fig. 8 shows the variation of predicted SPMI efficiency at $2000 \mathrm{rpm}$ and $20 \%$ of rated torque as a function of $I_{d}$. The predicted efficiency is approx. $86.5 \%$ for the $\max T / A$ algorithm (when $I_{d}$ is zero), while the efficiency is approx. $88.5 \%$ for the $\max T / V$ algorithm $\left(I_{d}=-140 \mathrm{~A}\right.$ rms $)$. In between these extremes, the partial-load machine efficiency peaks when $I_{d}=-80 \mathrm{~A} \mathrm{rms}$ at a value very close to the specified value of $93 \%$. This is a clear indication that choosing the optimum combination of $I_{d}$ and $I_{q}$ can have a very beneficial effect on maximizing the partial-load efficiency of the machine. These results will be discussed further based on the FEA results presented in the following section.

Figure 9 presents the calculated current vector trajectory for achieving the highest partial-load efficiency as the rotor speed is increased from 1000 to $10,000 \mathrm{rpm}$. By comparing this trajectory to the $\max T / A$ and $\max T / V$ current vector trajectories in Figs. 3 and 4, respectively, it can be observed that new trajectory adds a higher-level of negative $d$-axis current as a function of rotor speed compared to the $\max T / A$ trajectory in order to reduce the iron losses, but not as much $I_{d}$ as the $\max T / V$ algorithm would require.

Figure 10 shows the new predicted efficiency curve for the SPMI machine at $20 \%$ of rated torque when the current vector trajectory in Fig. 9 is applied as a function of rotor speed. The partial-load efficiency values are boosted at every speed compared to the values plotted in 


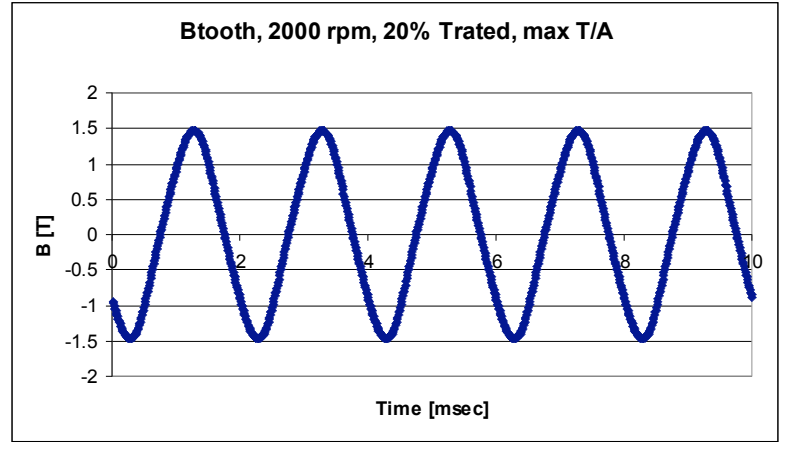

Fig. 11: Predicted stator tooth magnetic flux density waveform at $2000 \mathrm{rpm}$ and $20 \%$ rated output torque under $\max T / A$ operating conditions

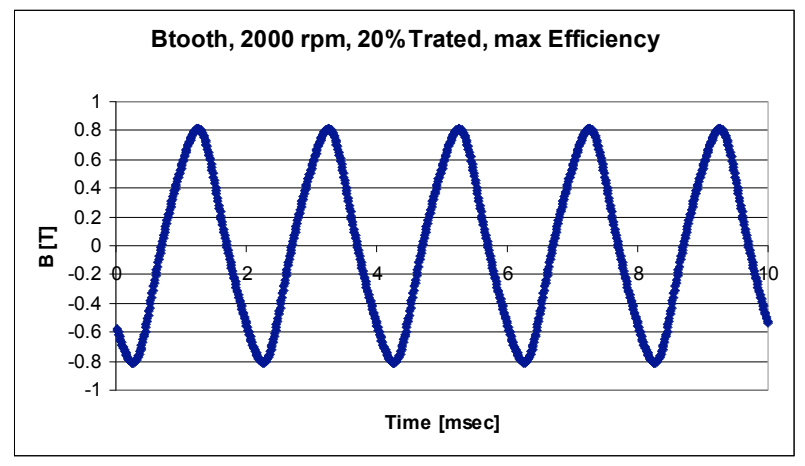

Fig. 13: Predicted stator tooth magnetic flux density waveform at $2000 \mathrm{rpm}$ and $20 \%$ rated output torque under max efficiency operating conditions

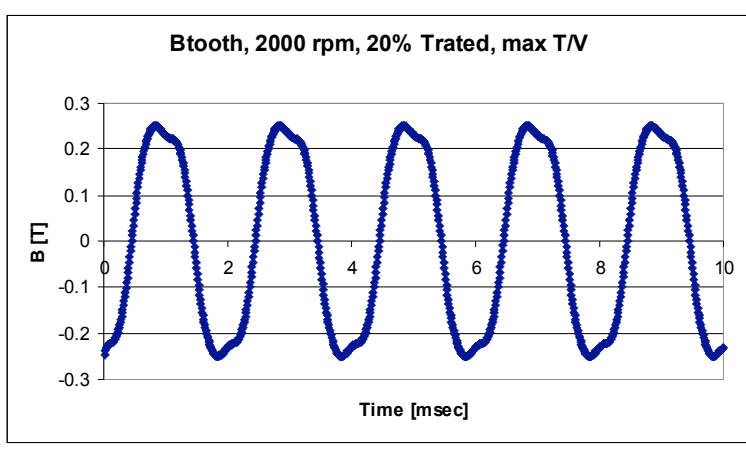

Fig. 12. Predicted stator tooth magnetic flux density waveform at $2000 \mathrm{rpm}$ and $20 \%$ rated output torque under $\max T / V$ operating conditions

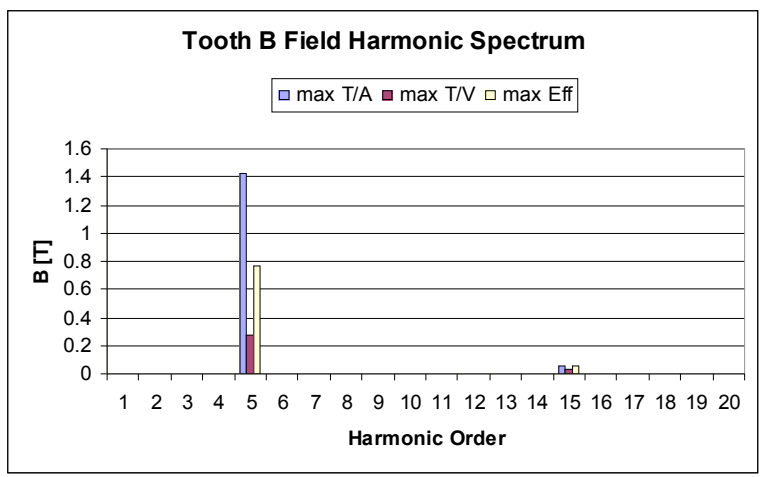

Fig. 14: Predicted harmonic spectra for stator tooth magnetic flux density at $2000 \mathrm{rpm}, 20 \%$ rated torque for the three operating conditions

Fig. 7 for the $\max T / A$ and $\max T / V$ trajectories. In fact, the results in Fig. 10 predict that the $S P M 1$ machine will be able to meet the minimum efficiency requirements (93\%) for $20 \%$ rated torque over the complete speed range.

\section{Finite Element Analysis Results for SPM1 Machine}

In order to verify the assumptions used in the analytical calculations of core losses and to gain more insights into the tradeoffs between the copper and core losses for maximizing the partialload efficiency, FEA simulations using MagNet 2D (Infolytica) were carried out. Three operating points at $2000 \mathrm{rpm}$ and $20 \%$ rated torque are considered. These points correspond to three distinct points on the partial-load efficiency curve shown in Fig. 8, representing max T/A (far right), $\max T / V$ (far left), and max efficiency operation at the peak of the curve.

The FEA-predicted magnetic flux density time-domain waveforms in the centers of the stator teeth are shown in Figs. 11 to 13 for the three highlighted operating points. The harmonic spectra of these stator-tooth flux density waveforms are presented in Fig. 14.

The first key observation drawn from these figures is that the magnetic flux density waveforms in the stator teeth are almost purely sinusoidal, as confirmed by the harmonic 
spectrum in Fig. 14. This result is striking since the fractional-slot concentrated windings produce many spatial harmonics in the airgap flux density waveform [14]. The sinusoidal waveshapes in Figs. 11 to 13 justify the sinusoidal approximation adopted for calculating the peak air gap magnetic flux density and, subsequently, for calculating the peak magnetic flux density in the stator teeth and yoke.

The second key observation drawn from comparing Figs. 11 and 12 is that there is a significant reduction (by almost $80 \%$ ) of the peak magnetic flux density in the stator tooth for the $\max T / V$ algorithm compared to the $\max T / A$ algorithm. This flux density reduction leads to a significant reduction of the predicted core losses in the stator teeth. This reduction in the stator core loss comes at the expense of an increase in the rms phase current amplitude (139.3 vs $30.6 \mathrm{~A} \mathrm{rms}$ ), and, hence, a corresponding increase in the copper losses, as discussed in the previous section. This result is consistent with the results shown earlier in Figs. 5 and 6.

Figure 13 shows the predicted stator tooth magnetic flux density waveforms under the max efficiency operating conditions. It can be observed that there is almost a $50 \%$ reduction in the stator tooth peak magnetic flux density compared to the max T/A case. At the same time, there is an increase in the phase current amplitude (76.4 vs $30.6 \mathrm{~A} \mathrm{rms).} \mathrm{This} \mathrm{blend} \mathrm{of} \mathrm{the} \mathrm{max} \mathrm{T/A} \mathrm{and}$ the $\max T / V$ algorithms yields the maximum partial-load efficiency for operation at $20 \%$ rated torque with a rotor speed of $2000 \mathrm{rpm}$.

\section{Algorithm Application to $6 \mathrm{~kW}$ FSCW machine}

Since the SPM1 machine discussed in the preceding sections of this report has not been built, an effort is being made to perform experimental verification tests for the partial-load efficiency algorithm using a different SPM machine that has already been fabricated. This $6 \mathrm{~kW}$ prototype machine (referred to in this report as SPM2) shares many of the most important features of the SPM1 machine including the use of fractional-slot concentrated stator windings. However, this 6 $\mathrm{kW}$ machine also embodies some important differences from the SPMI machine design that limits its effectiveness as a vehicle for performing these verification tests that will be discussed in the following section.

\section{A. $6 \mathrm{~kW}$ Prototype Machine Details}

The $6 \mathrm{~kW}$ prototype machine was designed and built for ORNL by UW-Madison and used to successfully demonstrate that fractional-slot concentrated winding (FSCW) surface PM machines can be used to achieve wide speed ranges of constant-power operation. Several of the key machine parameters are summarized in Table III. A comparison of the parameters in this table with those of the SPMI machine in Table II shows that these two machines share several important features in common including their pole number (30) and slot-per-pole-per-phase value $(2 / 5)$

A cross-section view of the basic repeating unit (5 rotor poles) of the SPM2 machine is provided in Fig. 15, and a photo of the prototype machine appears as Fig. 16. Closer examination of Tables II and III indicate that the key physical dimensions of the SPMI and $S P M 2$ machines including stator outer diameters and active lengths are very similar. This is very 
TABle III: 6 KW SPM2 MAChine Dimensions AND PARAMETERS

\begin{tabular}{|l|l|l|l|}
\hline Slots/Pole/Phase & $2 / 5$ & Slots & 36 \\
\hline Poles & 30 & Rotor Outer Radius [mm] & 88.6 \\
\hline Stator OD [mm] & 272 & Active length [mm] & 60 \\
\hline Total Length [mm] & 74.9 & Magnet Thickness [mm] & 13 \\
\hline Air-gap Thickness [mm] & 1.0 & Magnet Remanent Flux Density [T] & $0.55 @ 140^{0} \mathrm{C}$ \\
\hline Copper Mass [kg] & 2.3 & Magnet Mass [kg] & 3.5 \\
\hline Iron Mass [kg] & 8.1 & Total Mass [kg] & 14 \\
\hline
\end{tabular}

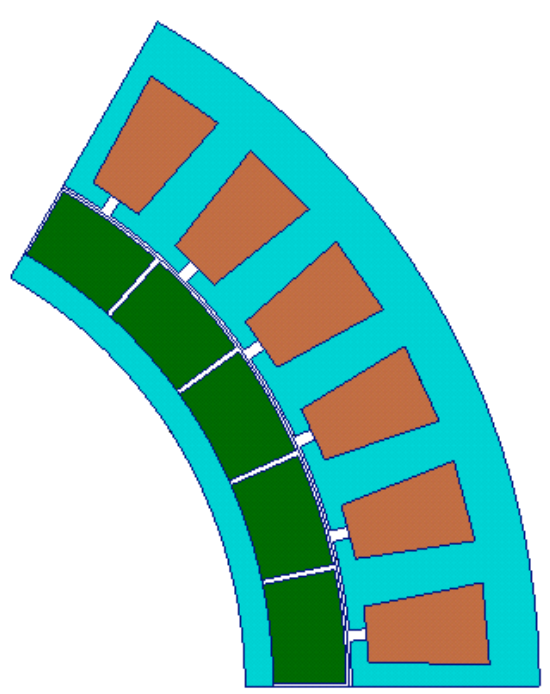

Fig. 15: Cross-section of the basic repeating unit (5 rotor poles) of the SPM2 machine

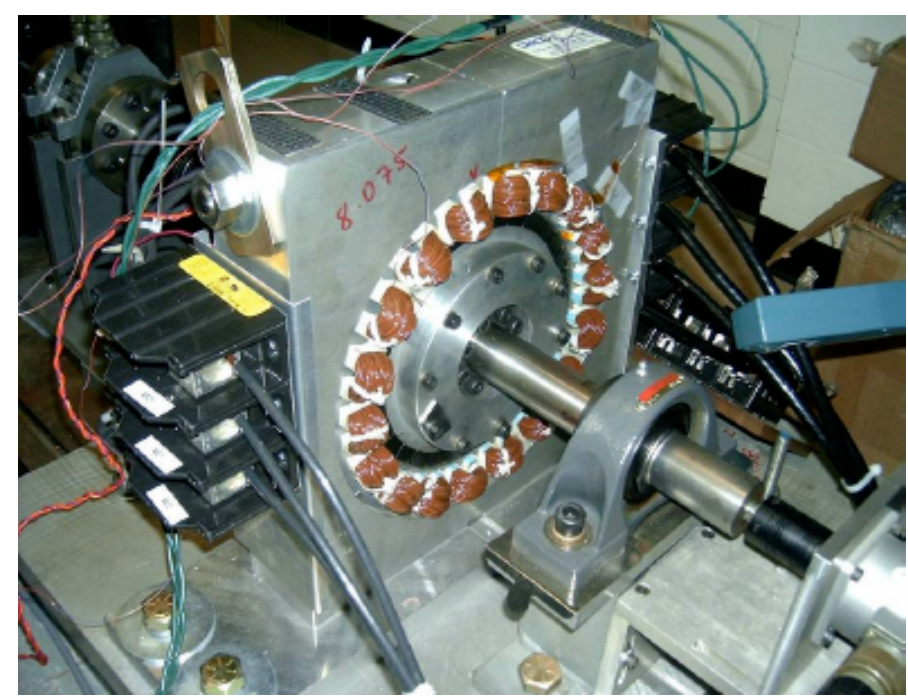

Fig. 16: View of prototype $S P M 2$ machine during testing at UW-Madison

striking since the SPMI machine has a continuous power rating $(30 \mathrm{~kW})$ that is five times larger than the corresponding value for the SPM2 machine $(6 \mathrm{~kW})$. The primary reason for the large difference in power density is that the SPM2 machine was designed with the primary objective of demonstrating the constant-power operating capabilities of this type of machine with conservative values of the stator current density and pole dimensions. In contrast, the SPM2 machine was purposely designed much more aggressively to demonstrate that the FSCW surface PM machine is capable of achieving high values of power density.

The significantly higher power density of the SPMI machine was achieved using a combination of different techniques. First, the corner point speed of the SPM1 machine is 2000 rpm while the corresponding corner speed of the prototype SPM2 machine is less than half of that speed (approx. $900 \mathrm{rpm}$ ), accounting for a doubling of the power density of the SPM1 machine for the same torque production. In addition, the SPMI machine is designed with a significantly higher value of stator winding current density than the SPM2 machine because it is specifically designed for a liquid-cooled stator fixture instead of air cooling. 
There are two more differences between the SPM1 and SPM2 machines that deserving noting in this discussion. First, the SPM1 machine is designed to minimize its volume and mass, making it necessary to drive more magnetic flux through smaller iron cross-sectional areas. As a result, the iron in the SPM1 machine is pushed deeper into saturation (i.e., higher values of maximum flux density $B$ ) than the $S P M 2$ machine.

Second, the SPM 2 machine was designed using bonded NdFeB magnets in order to minimize its eddy-current losses in the magnets, taking advantage of the high resistivity of bonded magnets. In contrast, the $S P M I$ machine is designed using sintered NdFeB magnets that have a significantly higher remanent flux density $(1.0 \mathrm{~T}$ vs. $0.55 \mathrm{~T}$ at $140 \mathrm{degC})$ at the price of significantly lower resistivity that increases its magnet eddy-current losses compared to the SPM1 machine. Unlike the SPM1 machine, no circumferential segmentation of the magnets was necessary in the SPM2 machine because of the much higher resistivity of the bonded magnets.

This discussion of the differences between the SPMI and SPM2 machines helps to set the stage for a key point made later in the paper that not all SPM machines are equally suitable for application of the partial-load efficiency algorithm. As will become more clear in the next section, the suitability of a machine for demonstrating a significant advantage by applying this algorithm depends on the presence of substantial iron core loss components that can be reduced by adding negative $d$-axis current (i.e., flux weakening) without adding too much copper losses to negate the reduction in iron losses.

\section{B. Predicted Performance of SPM2 Machine using New Algorithm}

\section{Analytical Approach}

A two-dimensional finite element analysis has been carried out to investigate the performance characteristics of the SPM2 machine in combination with the partial-load efficiency algorithm. The electromagnetic FEA programs MagNet2D (Infolytica) and JMag (JRI, Inc.) have been used in this part of the investigation to provide more accurate predictions of the magnetic fields and iron losses in the FSCW-SPM machine. In particular, the JMag program is capable of providing a point-by-point frequency spectrum calculation of the iron losses over the complete crosssection of the machine. Both hysteresis and eddy-current losses are calculated for the target machine, using iron loss characteristics provided by the lamination steel manufacturer. This approach provides improved accuracy for predicting the iron losses in such a machine at the price of longer calculation times.

In order to carry out this analytical investigation in anticipation of experimental tests, the torque level of the SPM2 machine is held constant at a value $(\sim 9 \mathrm{Nm})$ corresponding to $6 \mathrm{~kW}$ power delivery at the peak speed of $6000 \mathrm{rpm}$. Core, copper, and magnet losses are calculated at different speeds by varying the $d$-axis current. The torque production of the machine changes very little as a result of varying the $d$-axis current. Ideally, the output torque depends only on the $q$-axis current, but, in this case, the changing losses of the machine cause a secondary dependence of the torque production on the $d$-axis current amplitude. The total losses are plotted as a function of the $d$-axis current (which is negative) in order to investigate the changes in the machine efficiency. 


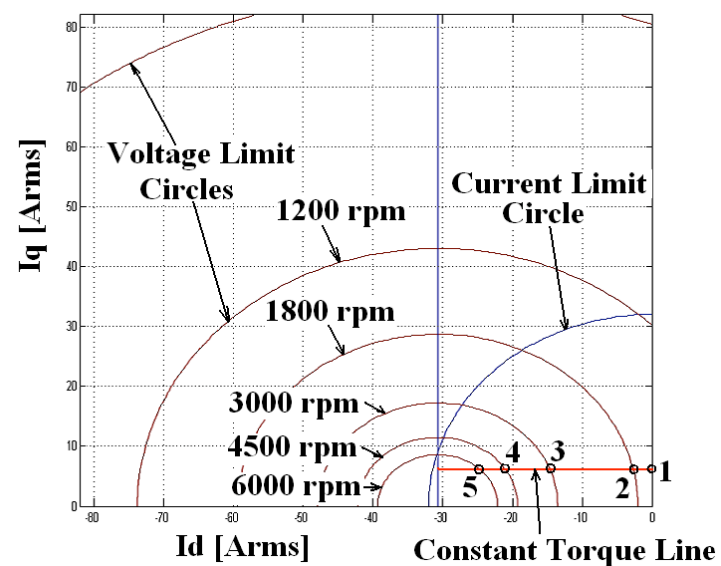

Fig. 17: Interaction of voltage limit circles and current limit circle to define MTPA operating points.

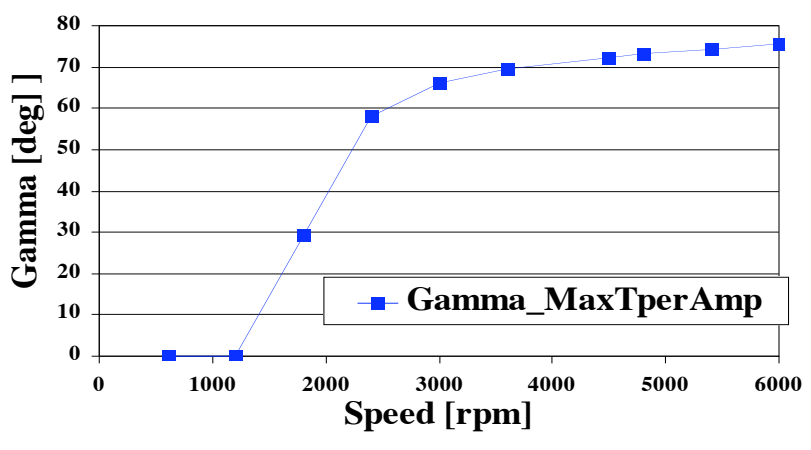

Fig. 18: Variation of current vector angle gamma $(\gamma)$ as a function of speed for MTPA operating points.

During this investigation, attention is focused on two categories of operating points: a) the maximum efficiency (ME) operating points; and b) the maximum-torque-per-Amp (MTPA) operating points. At low speeds, the MTPA operating point resides on the $q$-axis (i.e., $d$-axis current equals zero). Under these conditions, the current angle $\gamma$ measured between the $q$-axis and the current vector operating point $\left(I_{d}, I_{q}\right)$ equals zero. At elevated speed, the voltage constraint forces the MTPA operating point to move off of the $q$-axis into the second quadrant (see Fig. 17), causing current angle $\gamma$ to increase (Fig. 18). More specifically, the MTPA operating point is determined by the intersection of the voltage limit circle at that speed and the horizontal line that has the required $q$-axis current amplitude to develop the required torque. At this intersection, the negative $d$-axis current is just sufficient to reduce the machine's terminal voltage to fall within the voltage limit set by the dc bus voltage value. This MTPA operating point corresponds to the lowest current amplitude required to develop the specified torque, thereby earning the maximum torque-per-Amp designation, while meeting the voltage constraint.

As indicated in Fig. 17, the radius of the voltage limit circle monotonically shrinks as the rotor speed is increased, causing the intersection of the horizontal line in Fig. 17 and the corresponding voltage limit circle for each particular speed to gradually shift to the left as the speed increases (note points 1 to 5 in the figure). As a result, the current angle $\gamma$ also increases monotonically with speed as indicated in Fig. 18.

On the other hand, the maximum efficiency point is the current plane operating point that provides the maximum machine efficiency while delivering the required torque and meeting the applicable voltage constraint. That is, the tradeoff between the copper and non-copper losses in the machine is most favorable at this operating point in order to minimize the total losses while still producing the required torque.

In the following presentation of analytical results, the effects of $d$-axis current on the machine losses and efficiency will first be observed while ignoring the impact of the voltage constraints. Next, the dependence speed on these loss and efficiency characteristics will be presented. Finally, the impact of introducing the voltage constraints on the achievable efficiency improvements will be investigated. 


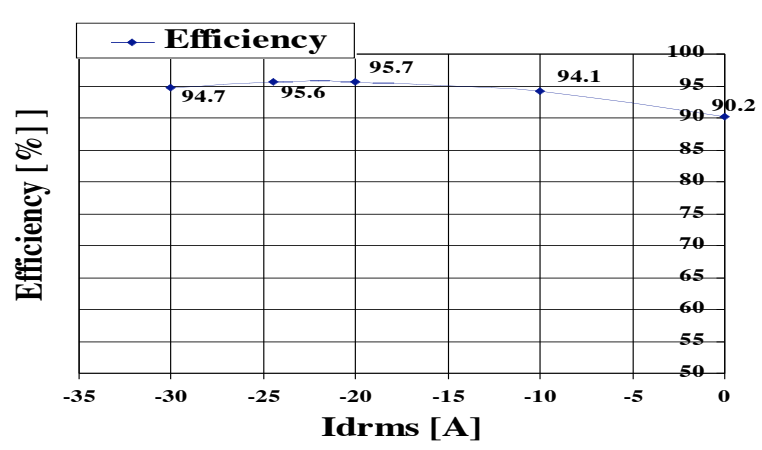

(a)

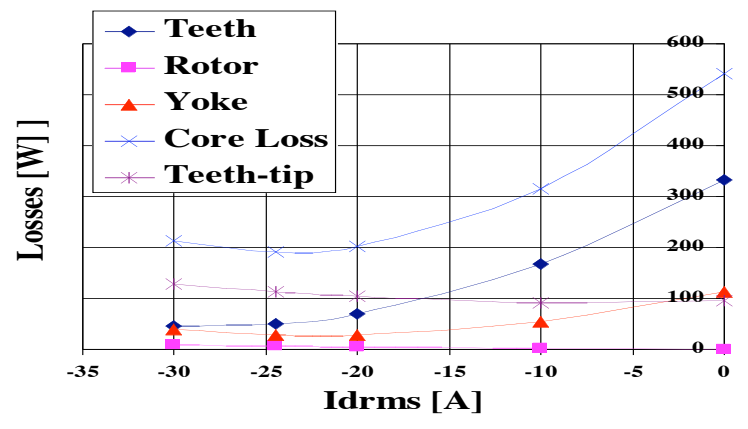

(c)

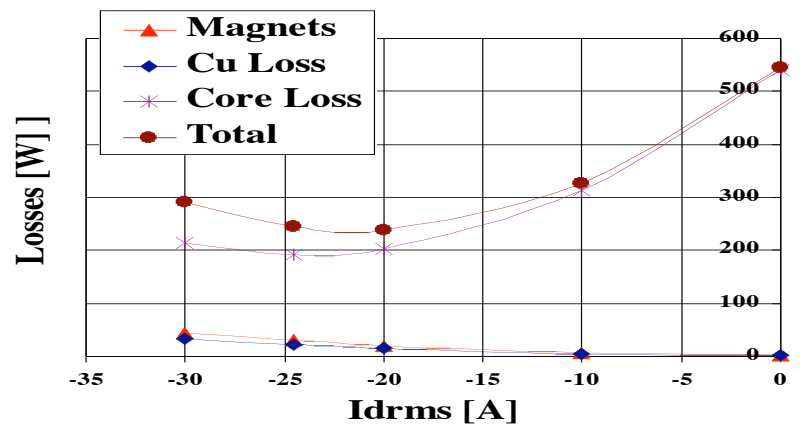

(b)

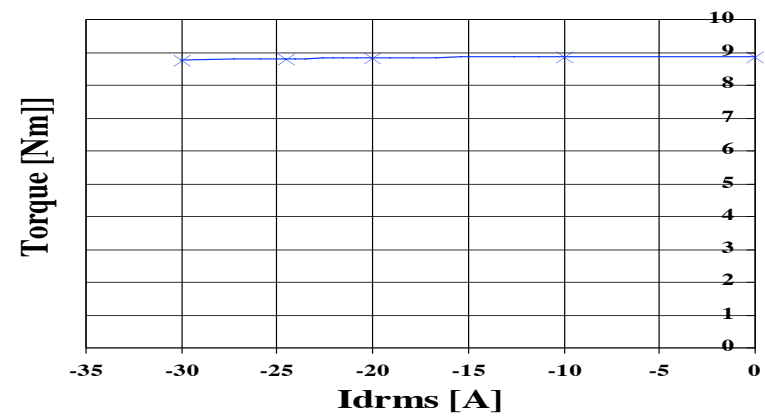

(d)

Fig. 19: SPM2 machine performance characteristics using partial-load efficiency algorithm at $6000 \mathrm{rpm}$, all as a function of $I_{d r m s}$ : (a) machine efficiency; (b) loss component breakdown; (c) core loss location breakdown; and (d) output torque

\section{Predicted Efficiency Improvement without Voltage Constraint}

Figure 19 presents the key SPM2 machine loss and efficiency characteristics as a function of the rms $d$-axis current $I_{d r m s}$ (always negative in polarity) for constant torque (power) operation at $6000 \mathrm{rpm}$, the maximum speed. This torque value (see Fig. 19d) corresponds to $20 \%$ of the rated torque for the $6 \mathrm{~kW} \mathrm{SPM2}$ machine. The magnitude of the $d$-axis current is varied between zero and the machine's characteristic current, which is in the vicinity of 30 Arms.

Figure 19a shows that the predicted efficiency of the SPM2 machine rises modestly from $90.2 \%$ when no $d$-axis current is applied $\left(I_{d r m s}=0\right)$ to a maximum predicted value of $95.7 \%$ when the $d$-axis current is increased (in negative polarity) to -22.5 Arms. While this increase is not as large as the predicted efficiency increases for the SPM1 machine, it does indicate that the partialload efficiency algorithm can have some beneficial impact in the SPM2 machine.

When the $d$-axis current is zero (i.e., only $q$-axis current is applied), the core losses represent the dominant contributor to the total machine losses as shown in Fig. 19b. Increasing the amount of negative $d$-axis current offsets the magnet flux (i.e., flux weakening) and decreases the resulting flux density in the teeth and yoke. This reduces the core losses in the stator teeth and yoke as shown in Figs. 19b and 19c. On the other hand, Fig. 19c also indicates that the teeth-tip losses first decrease up to $d$-axis currents of approx. -10 Arms before starting to increase again when higher values of negative $d$-axis current are applied. 


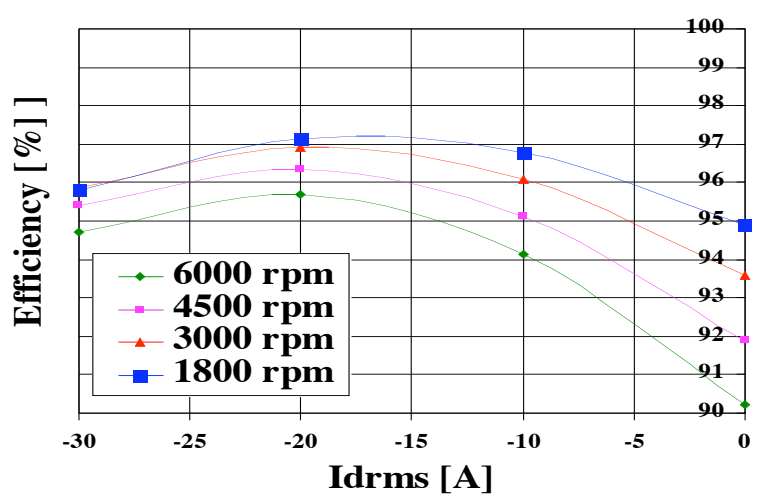

Fig. 20: Predicted SPM2 machine efficiency as a function of $I_{d r m s}$ for $20 \%$ rated torque production at four rotor speeds.

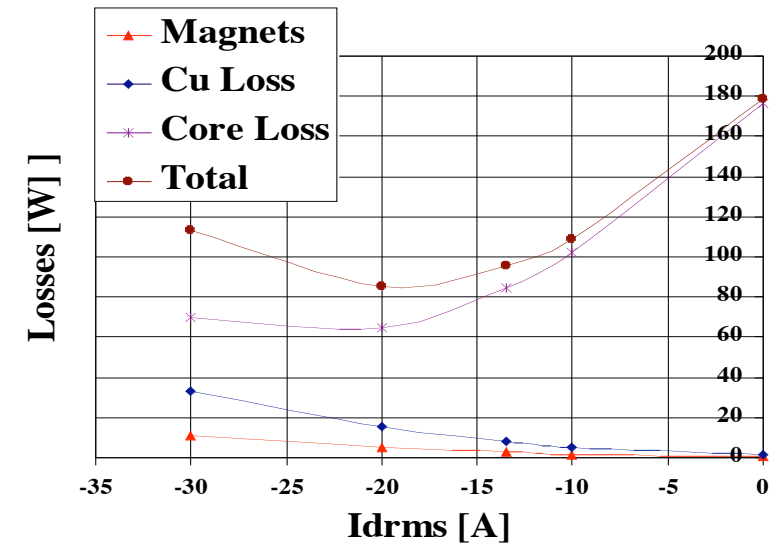

Fig. 22: Predicted SPM2 machine loss breakdown as a function of negative $d$-axis current for operation at 3000 rpm

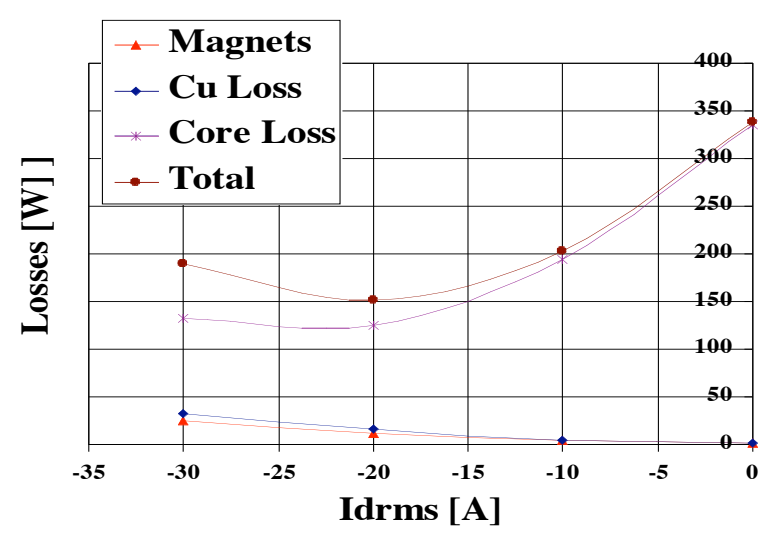

Fig. 21: Predicted SPM2 machine loss breakdown as a function of negative $d$-axis current for operation at $4500 \mathrm{rpm}$

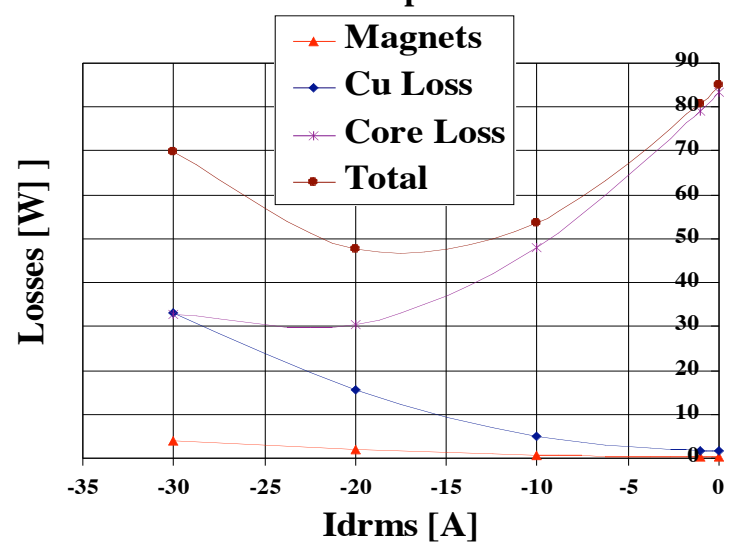

Fig. 23: Predicted SPM2 machine loss breakdown as a function of negative $d$-axis current for operation at $1800 \mathrm{rpm}$

The copper losses (Fig. 19b) increase monotonically with increasing $d$-axis current but form a small percentage of the total losses at high speed due to the dominance of the non-copper losses which increase significantly at high speeds. Similarly, the magnet losses increase monotonically with increasing amplitudes of negative $d$-axis current, although the combined copper and magnet losses continue to be secondary contributors to the total losses for all values of $I_{d r m s}$.

The effect of combining all of these loss components is the total loss curve in Fig. 19b that features a distinct minimum at a particular value of $d$-axis current (-22.5 Arms in this case), identifying the maximum efficiency operating point. At this particular operating point, the decrease in the stator tooth and yoke losses for an incremental increase in the negative $d$-axis current is exactly offset by the increase in the combined copper, magnet, and tooth tip losses. Beyond this point, any further increase in the negative $d$-axis current results in a net loss increase, lowering the efficiency below its peak value. 


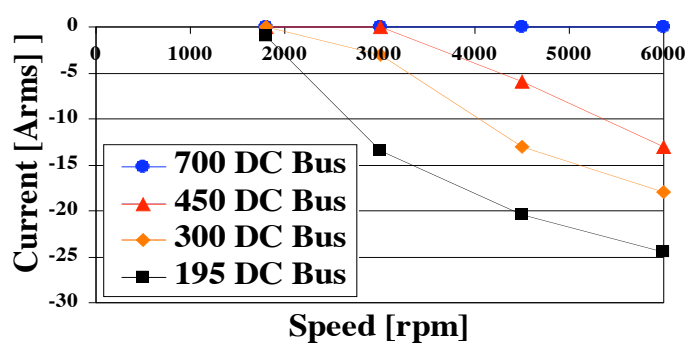

Fig 24: Minimum $d$-axis current for SPM2 machine as a function of speed with de bus voltages of 195 , 300,450 , and $700 \mathrm{Vdc}$

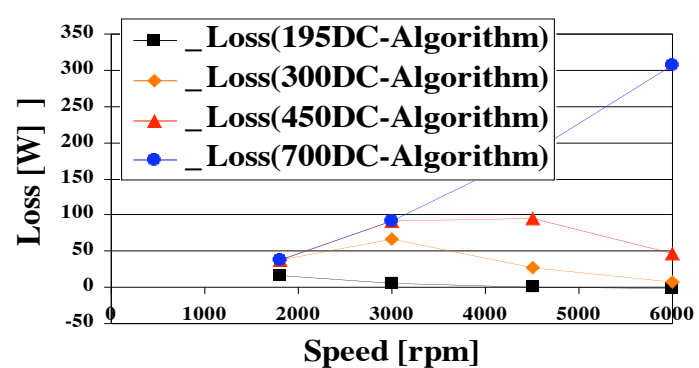

Fig 25: Improvement of losses for 195, 300, 400, 500, 600 and 700 DC Bus constraint

As the speed is reduced below $6000 \mathrm{rpm}$, the iron and magnet losses drop so that the copper losses become a larger fraction of the total machine losses. As a result, it is not surprising that the predicted machine efficiency gradually increases as the rotor speed is decreased. Since the iron losses become less important as the speed drops, another important observation for this discussion is that the predicted efficiency improvement achievable from applying the partial-load efficiency algorithm also gradually decreases at lower speeds.

Both of these trends are apparent in the set of parametric efficiency curves in Fig. 20 for four rotor speeds. The positive conclusion derived from observing these curves is that the partialefficiency algorithm will provide a net efficiency increase by adding negative $d$-axis current for operation at all four speeds. On the other hand, the improvement becomes increasingly modest as the speed is reduced. Looking at the two extremes of the speed range in Fig. 20, the achievable efficiency increase from its value for $I_{d r m s}=0$ is approx. $5.5 \%$ at $6000 \mathrm{rpm}$, corresponding to a loss reduction in the vicinity of $330 \mathrm{~W}$. At the other extreme, the corresponding efficiency increase at $1800 \mathrm{rpm}$ is only $2.2 \%$. This improvement looks even more meager in absolute terms, corresponding to a loss reduction of only $40 \mathrm{~W}$ at this low speed. (Note that the output power drops to $1.8 \mathrm{~kW}$ at $1800 \mathrm{rpm}$ because the torque is held at $20 \%$ of its rated value.)

Figures 21 to 23 provide loss component breakdowns as a function of the negative $d$-axis current for $4500 \mathrm{rpm}, 3000 \mathrm{rpm}$, and $1800 \mathrm{rpm}$ for comparison with the loss breakdown for 6000 rpm plotted in Fig. 19b. Consistent with the discussion above, it is very apparent that the iron loss amplitude drops dramatically from approximately $550 \mathrm{~W}$ to $85 \mathrm{~W}$ for the $I_{d r m s}=0$ condition as the speed is reduced from $6000 \mathrm{rpm}$ to $1800 \mathrm{rpm}$. In contrast, the copper losses are unchanged because the torque output is being held constant.

\section{Predicted Efficiency Improvement including Voltage Constraint}

It is important to remind readers that the results in Figs. 19 to 23 are all presented for somewhat idealized operating conditions because the impact of the inverter voltage constraint has been ignored. As discussed earlier in this section using Figs. 17 and 18, the impact of the finite dc bus voltage is to gradually increase the minimum value of negative $d$-axis current from 
zero at low speeds to a substantial non-zero value at high speeds. This means that operation with $I_{d r m s}=0$ on the $q$-axis is unattainable above a certain finite speed.

The minimum value of negative $d$-axis current at any particular speed in this elevated range monotonically increases (in magnitude) as the bus voltage is reduced. The minimum values of negative $d$-axis current are plotted in Fig. 24 for the SPM2 machine as a function of speed for four values of dc bus voltage ranging from $195 \mathrm{Vdc}$ to $700 \mathrm{Vdc}$. Considering the lowest voltage curve for $195 \mathrm{Vdc}$, the minimum negative $d$-axis current becomes non-zero for all speeds above $1800 \mathrm{rpm}$, rising to nearly -25 Arms at $6000 \mathrm{rpm}$. At the other extreme of bus voltage values, operation with $I_{d r m s}=0$ is still achievable over the full speed range up to $6000 \mathrm{rpm}$ when the dc bus voltage is raised to $700 \mathrm{Vdc}$.

Returning to Fig. 19a, the impact of the voltage constraint is that operation with low values of negative $d$-axis current on the right side of this curve becomes increasingly restricted as the bus voltage is reduced. For the case of operation at $6000 \mathrm{rpm}$ (worst case for this machine), the operating point for maximum efficiency in Fig. 19a with $I_{d r m s}=-22.5$ Arms becomes unreachable if the bus voltage is reduced below approx. $250 \mathrm{Vdc}$.

Because of this significant restriction on achievable operating points imposed by the finite bus voltage constraint, the efficiency curves in Figs. 19a and 20 become somewhat misleading about the amount of efficiency that can be actually demonstrated in the lab by applying the partial-load efficiency algorithm. That is, claiming a 5.5\% efficiency increase at $6000 \mathrm{rpm}$ is misleading unless the bus voltage is sufficiently high (i.e., in the vicinity of $700 \mathrm{Vdc}$ ) so that operation at $I_{d r m s}=0$ can be demonstrated as the baseline for comparison. A more realistic basis for evaluating the achievable efficiency increase (or, equivalently, loss reduction) at any speed is to compare the efficiency/loss values at the maximum-efficiency operating point for that speed (i.e., peaks of the curves in Figs. 19a and 20) with the efficiency/losses at the minimum $d$-axis current operating point achievable for the chosen value of dc bus voltage (Fig. 24). This seems reasonable since this corresponds to the efficiency or loss improvement that can be actually demonstrated in the lab during verification tests.

Using the approach described in the preceding paragraph, Fig. 25 plots the achievable efficiency/loss improvement using the partial-load efficiency algorithm as a function of speed for the same four values of dc bus voltage used in Fig. 24. The curve for $700 \mathrm{Vdc}$ represents the best improvement that can be achieved because, as noted above, the $I_{d r m s}=0$ operating point is reachable at all speeds up to and including $6000 \mathrm{rpm}$. As a result, a predicted loss reduction exceeding $300 \mathrm{~W}$ should be demonstrable in the lab at $6000 \mathrm{rpm}$ with this high dc bus voltage.

Unfortunately, $700 \mathrm{Vdc}$ is much higher than the bus voltage values that are likely to be available in the lab during verification testing, and much higher than the bus voltage that this machine was designed to use, which is much closer to $200 \mathrm{Vdc}$. However, operation with a dc bus voltage of $195 \mathrm{Vdc}$ is not an attractive option because the corresponding curve in Fig. 25 indicates that the operating range for negative $d$-axis current is severely restricted to the point that the demonstrable loss improvement drops to virtually zero. The predicted loss improvements that will be demonstrable with intermediate values of dc bus voltage at either 300 or $450 \mathrm{Vdc}$ fall between these two extremes. That is, the loss reduction is non-zero at all speeds 
Table IV: Predicted Change in DC Bus Current for Loss Improvements in Fig. 25

\begin{tabular}{|l|c|c|c|c|}
\hline DC Bus & $195 \mathrm{~V}$ & $300 \mathrm{~V}$ & $450 \mathrm{~V}$ & $700 \mathrm{~V}$ \\
\cline { 1 - 4 } Speed & & & & \\
\hline $1800 \mathrm{rpm}$ & 0.09 & 0.13 & 0.09 & 0.06 \\
\hline $3000 \mathrm{rpm}$ & 0.03 & 0.23 & 0.21 & 0.13 \\
\hline $4500 \mathrm{rpm}$ & 0.00 & 0.09 & 0.21 & 0.27 \\
\hline $6000 \mathrm{rpm}$ & -0.01 & 0.03 & 0.11 & 0.44 \\
\hline
\end{tabular}

of interest above $1800 \mathrm{rpm}$, but the amplitudes of these loss improvements are significantly less than what can be demonstrated using a $700 \mathrm{Vdc}$ bus at speeds near the upper end of the speed range.

\section{Measurement of Efficiency Improvement using SPM2 Machine}

A practical question that arises is whether the predicted loss improvements in Fig. 25 will be conveniently measurable in the laboratory. This is a serious question because loss measurements are very sensitive to the accuracy of the available instrumentation, and accurate measurements of input power at the machine terminals can be demanding because of the high-frequency PWM waveforms that are used.

One approach that is under consideration is to measure the dc bus current as a surrogate for the machine input power. This is particularly practical if the measurement of interest is a difference in machine input power for two operating conditions rather than its absolute value. More specifically, assume that the output torque and power are being held constant by adjusting the amplitude of the $q$-axis current applied to the machine. If the amplitude of the $d$-axis current is changed by the drive controller, two consecutive readings of the dc bus current before and after the change could be used to determine the change in the machine losses for these two operating conditions. The raw value of bus power difference (equal to the product of the dc bus voltage and the change in the bus current, or $V_{d c} * \Delta I_{d c}$ ) would have to be corrected for the predicted change in the inverter losses for these two operating points in order to isolate the change in machine losses, but that correction can likely be achieved with reasonable accuracy and confidence.

Assuming that this is a reasonable approach to measuring the change in machine losses, the next question is whether the predicted changes in the dc link current will be measurable in practice. With this question in mind, Table IV has been prepared to show the predicted changes in de link current that correspond to the loss improvement values plotted in Fig. 25 for different combinations of dc bus voltage and speed. (These values do not include any contribution due to the change in inverter losses that would have to be corrected.) One interesting point to note is that the changes in dc link current are inversely proportional to the dc bus voltage for any given loss value, so that the table values for $700 \mathrm{Vdc}$ are still relatively small even though the absolute values of the loss improvements increase compared to the lower bus voltage values.

As a result of these combined effects, all of the table entries are less than $0.5 \mathrm{~A}$, indicating that careful instrumentation will be required to capture these differences with sufficient 


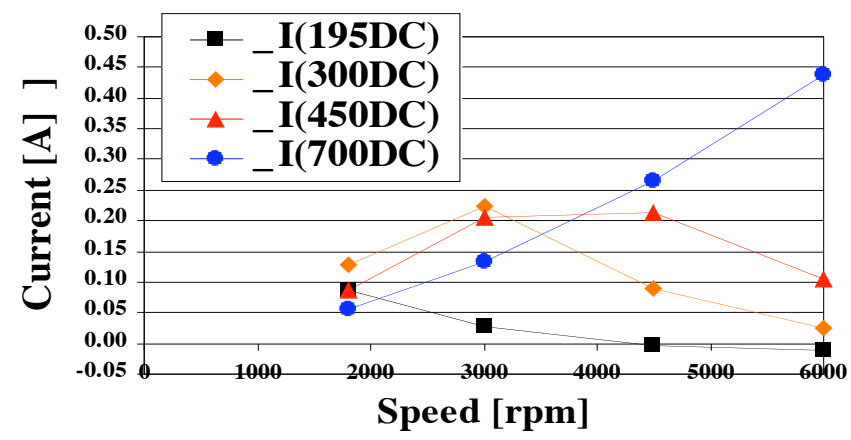

Fig 26: Predicted reduction in dc bus current $\Delta I_{d c}$ by applying the partial-load efficiency algorithm to the $S P M 2$ machine as function of speed and dc bus voltage.

confidence in the results. In addition, high stability of the dynamometer operating points will be critical to successfully making these measurements.

The green cells in Table IV are initial predictions of the current changes that are large enough to be measured with reasonable confidence in the laboratory, assuming careful instrumentation. More specifically, current changes less than $100 \mathrm{~mA}$ are considered to fall below the measurable threshold from a practical standpoint. On this basis, the table entries support the earlier statement that the likelihood of being able to demonstrate any efficiency improvement with a dc bus voltage of $195 \mathrm{Vdc}$ is low. On the other hand, the table entries suggest that loss reductions will be measurable with careful instrumentation for higher bus voltages of 300 or $450 \mathrm{Vdc}$.

Figure 26 provides a graphical presentation of the data in Table IV. With the exception of the curve for $700 \mathrm{Vdc}$, the predicted dc link current reduction values decrease as the speed is increased above some threshold value. The speed at which each curve begins to drop is consistent with the earlier discussion identifying the threshold speeds above which the minimum value of negative $d$-axis current becomes non-zero (Fig. 24) because of the voltage constraint, restricting the efficiency improvement that can be demonstrated for any higher speeds.

Assuming that a bus voltage of $300 \mathrm{Vdc}$ can be used for the tests, the corresponding curve in Fig. 26 indicates that the largest dc current change (approx. $0.2 \mathrm{~A}$ ) will occur in the vicinity of $3000 \mathrm{rpm}$. Above this speed, the impact of the voltage constraint becomes increasingly negative on the demonstrable loss improvement using the partial-load efficiency algorithm, resulting in the predicted drop in $\Delta I_{d c}$ amplitude.

\section{Conclusions}

This report has summarized the progress made to date in developing a new control algorithm for surface PM synchronous machines to improve their efficiencies during high-speed operation under partial-load conditions. As described in the preceding sections, the basic concept for this algorithm is rather straightforward for SPM machines. More specifically, negative $d$-axis current is added to depress the magnetic flux levels in the machine (i.e., flux weakening) in order to reduce the iron losses sufficiently to minimize the total machine losses. The fact that $d$-axis 
current does not contribute to torque production in SPM machines makes the application of the algorithm particularly convenient since the torque amplitude and the flux weakening are controlled independently by the $q$ - and $d$-axis current values, respectively.

This report has described the predicted results of applying this partial-load efficiency algorithm to two different fractional-slot concentrated winding (FSCW) surface PM machines. For the $55 \mathrm{~kW}$ (peak) SPM1 machine, introduction of the algorithm is predicted to have a significant beneficial impact in improving the partial-load (20\% rated load) efficiency, particularly at speeds in the vicinity of the corner point speed. In this speed range, the new algorithm is predicted to raise the operating efficiency by $6.5 \%$ compared to the baseline maximum torque-per-Amp (MTPA) control algorithm.

Since the $55 \mathrm{~kW} S P M 1$ machine has not been built, attention has subsequently been turned to the $6 \mathrm{~kW} S P M 2$ machine that has been built as a prototype machine for ORNL and is available for testing. This $S P M 2$ machine also uses fractional-slot concentrated windings and shares many features in common with the SPM1 machine except that its power density is much lower than that of the SPM1 machine. As a result, the amplitudes of the individual machine loss components (i.e., copper, iron, magnet losses) are noticeably different in the two machines, including their percentages of the total losses in each machine.

Analytical results from applying the partial-load efficiency algorithm to the $6 \mathrm{~kW} S P M 2$ machine are somewhat mixed. Unlike the SPM1 machine, the analysis indicates that the benefits of applying the partial-load efficiency algorithm are significantly less in the vicinity of the corner point speed. More specifically, the predicted efficiency improvement at $1800 \mathrm{rpm}$ resulting from introduction of the algorithm is only $2.2 \%$, down considerably from the $6.5 \%$ figure noted above for the SPM1 machine. The primary reason for the difference is that the iron losses in the SPM2 machine are significantly lower in the SPM2 machine since the iron is not pushed as far into saturation as in the $S P M 1$ machine, which was designed to maximize its power density. Since the iron losses are significantly lower in the SPM2 machine without the partial-load efficiency algorithm, there is less improvement that can be achieved by introducing the algorithm.

Despite this limitation imposed by the design characteristics of the SPM2 machine, there is still reason for optimism that the basic validity of the algorithm can still be demonstrated in the laboratory using the prototype SPM2 machine. As discussed in Section VI of this report, the success of this testing will depend on the availability of appropriate instrumentation in the laboratory to accurately measure and confirm the expected modest efficiency improvement associated with activation of the partial-load efficiency algorithm. Even though the loss reduction is small in the $S P M 2$ machine, its successful verification will build confidence in our ability to achieve much larger efficiency improvements in more aggressively-designed machines such as the SPM1 machine whenever they might be built in the future.

In light of this discussion, key results of this investigation can be summarized as follows:

- The partial-load efficiency algorithm is designed to improve the operating efficiency of SPM machines under partial-load operating conditions by using negative $d$-axis current to reduce the magnetic flux amplitude in the machine stator and rotor iron, thereby reducing the machine's iron losses. 
- On the basis of the analytical results accumulated to date, the partial-load efficiency algorithm is capable of improving the baseline machine efficiency using maximum torqueper-Amp control by $5 \%$ or more in some SPM machines when operating in the vicinity of the corner point speed.

- All SPM machines will not be equally good candidates for introduction of this partial-load efficiency algorithm. The best candidates are expected to be SPM machines that have been designed to achieve high power densities, resulting in high magnetic flux densities in the machine stator and rotor iron that significantly increase the iron losses during MTPA control operation.

At the time of this report submission, plans are still in place to test the prototype SPM2 machine during the first quarter of 2007 in order to investigate the operating characteristics of the machine when the partial-load efficiency algorithm is activated. It is hope that this testing will provide the desired experimental verification of this concept as well as yielding deeper insights into how the algorithm can be applied most effectively in future SPM machines.

\section{Acknowledgements}

The authors wish to thank several of their colleagues who have contributed in many valuable ways to the development of the technical material presented in this report. They include Dr. Ayman EL-Refaie at GE Global Research Center in Niskayuna, NY; Seok-hee (Sam) Han and Jagadeesh Tangudu who are doctoral graduate students at UW-Madison, and Prof. Wen L. Soong at the University of Adelaide, Adelaide, Australia. We also wish to thank Dr. John McKeever and Laura Marlino at Oak Ridge National Laboratory for their helpful advice and consistent support of this work. 


\section{References}

[1] A.M. EL-Refaie, and T.M. Jahns, "Optimal Flux Weakening in Surface PM Machines Using Concentrated Windings", IEEE Trans. Industry Applications, vol. 41, May-Jun 2005, pp. 790-800.

[2] A.M. EL-Refaie, and T.M. Jahns, P.J. McCleer, and J.W. McKeever, "Experimental Verification of Optimal Flux Weakening in Surface PM Machines Using Concentrated Windings", IEEE Trans. Industry Applications, vol. 42, March-April 2006, pp. 443-453.

[3] J. Cros, P. Viarouge, "Synthesis of High Performance PM Motors with Concentrated Windings", IEEE Trans. Energy Conversion, vol. 17, June 2002, pp. 248-253.

[4] F. Magnussen, C. Sadarangani, "Winding Factors and Joule Losses of Permanent Magnet Machines with Concentrated Windings", in Proc. of 2003 IEEE Intl. Elec. Mach. and Drives Conf. (IEMDC'03), vol.1, Madison, WI, pp. 333-339, June 2003.

[5] Z.Q. Zhu, D. Howe, "Influence of Design Parameters on Cogging Torque in Permanent Magnet Machines", IEEE Trans. Energy Conversion, vol. 15, December 2000, pp. 407-412.

[6] K. Atallah, D. Howe, P.H. Mellor, and D.A. Stone, "Rotor Loss in Permanent-Magnet Brushless AC Machines", IEEE Trans. Ind. Appl., vol. 36, Nov-Dec 2000, pp. 1612-1618.

[7] D. Ishak, Z. Q. Zhu, and D. Howe, "Analytical Prediction of Rotor Eddy Current Losses in Permanent Magnet Brushless Machines with All Teeth and Alternate Teeth Windings Part I: Polar Co-ordinate Model," in Proc. 7th International Conference on Electrical Machines and Systems (ICEMS'04), CD-ROM, 2004.

[8] D. Ishak, Z. Q. Zhu, and D. Howe, "Analytical Prediction of Rotor Eddy Current Losses in Permanent Magnet Brushless Machines with All Teeth and Alternate Teeth Windings Part II: Rectangular Co-ordinate Model," in Proc. 7th International Conference on Electrical Machines and Systems (ICEMS'04), CD-ROM.

[9] W. Soong, T.J.E. Miller, "Field Weakening Performance of Brushless Synchronous AC Motor Drives", IEE Proceedings-Electric Power Applications, vol. 141, November 1994, pp. 331-340.

[10] Z. Q. Zhu, Y.S. Chen, and D. Howe, "Iron Loss in Permanent-Magnet Brushless AC Machines Under Maximum Torque per Ampere and Flux Weakening Control," IEEE Trans. Magnetics, vol. 38, September 2002, pp. 32853287.

[11] Shigeo Morimoto, Yi Tong, Yoji Takeda, and Takao Hirasa, "Loss Minimization Control of Permanent Magnet Synchronous Motor Drives," IEEE Trans. Industrial Electronics, vol. 41, October 1994, pp. 511-517.

[12] C. Cavallaro, A.O. Di Tommaso, A. Raciti, G.R. Galluzzo, and M. Trapanese, "Efficiency Enhancement of Permanent-Magnet Synchronous Motor Drives by Online Loss Minimization Approaches," IEEE Trans. Industrial Electronics, vol. 52, August 2005, pp. 1153-1160.

[13] http://www.uscar.org/freedomcar/

[14] A.M. EL-Refaie, T.M. Jahns, and D.W. Novotny, "Analysis of Surface Permanent Magnet Machines Equipped with Concentrated Windings", IEEE Trans. Energy Conversion, vol. 21, Mar. 2005, pp. 34-43.

[15] A.G. Jack, B.C. Mecrow, P.G. Dickinson, D. Stephenson, J. S. Burdess, N. Fawcett and J.T. Evans, "Permanent Magnet Machines with Powdered Iron Cores and Pressed Windings", IEEE Trans. Industry Applications, vol. 36, July/August 2000, pp. 1077-1084.

[16] C. Mi, G.R. Slemon, and R. Bonert, "Modeling of Iron Losses of Permanent-Magnet Synchronous Motors", IEEE Trans. Industry Applications, vol. 39, May/June 2003, pp. 734-742.

[17] D.W. Novotny and T.A. Lipo, Vector Control and Dynamics of AC Drives, New York: Oxford University Press, 1996. 


\section{DISTRIBUTION}

\section{Internal}

$\begin{array}{ll}\text { 1. } & \text { D. J. Adams } \\ \text { 2. } & \text { K. P. Gambrell } \\ \text { 3. } & \text { E. C. Fox } \\ \text { 4. } & \text { L. D. Marlino }\end{array}$
5. J. W. McKeever

6. M. Olszewski

7. Laboratory Records

\section{External}

8. R. Al-Attar, DCX, raa9@dcx.com.

9. T. Q. Duong, U.S. Department of Energy, EE-2G/Forrestal Building, 1000 Independence Avenue, S.W., Washington, D.C. 20585.

10. R. R. Fessler, BIZTEK Consulting, Inc., 820 Roslyn Place, Evanston, Illinois 60201-1724.

10. K. Fiegenschuh, Ford Motor Company, Scientific Research Laboratory, 2101 Village Road, MD2247, Dearborn, Michigan 48121.

12. V. Garg, Ford Motor Company, 15050 Commerce Drive, North, Dearborn, Michigan 481201261.

13. G. Hagey, Sentech, Inc., 501 Randolph St., Williamsburg, Virginia 23185.

14. T. M. Jahns, The University of Wisconsin-Madison, 2559A Engineering Hall, 1415 Engineering Drive, Madison, Wisconsin 53706.

15. E. Jih, Ford Motor Company, Scientific Research Laboratory, 2101 Village Road, MD-1170, Rm. 2331, Dearborn, Michigan 48121.

16. K. J. Kelly, National Renewable Energy Laboratory, 1617 Cole Boulevard, Golden, Colorado 80401.

17. A. Lee, Daimler Chrysler, CIMS 484-08-06, 800 Chrysler Drive, Auburn Hills, Michigan 483262757.

18. F. Liang, Ford Motor Company, Scientific Research Laboratory, 2101 Village Road, MD1170, Rm. 2331/SRL, Dearborn, Michigan 48121.

19. M. W. Lloyd, Energetics, Inc., 7164 Columbia Gateway Drive, Columbia, Maryland 21046.

20. M. Mehall, Ford Motor Company, Scientific Research Laboratory, 2101 Village Road, MD-2247, Rm. 3317, Dearborn, Michigan 48124-2053.

21. J. A. Montemarano, Naval Surfae Warfare Center, Carderock Division; Code 642, NSWD, 9500 MacArthur Boulevard; West Bethesday, Maryland 20817.

22. N. Olds, United States Council for Automotive Research (USCAR),nolds@uscar.org

23. P. B. Reddy, The University of Wisconsin-Madison, 2559A Engineering Hall, 1415 Engineering Drive, Madison, Wisconsin 53706.

24. J. Rogers, Chemical and Environmental Sciences Laboratory, GM R\&D Center, 30500 Mound Road, Warren, Michigan 48090-9055.

25. S. A. Rogers, U.S. Department of Energy, EE-2G/Forrestal Building, 1000 Independence Avenue, S.W., Washington, D.C. 20585.

26. G. S. Smith, General Motors Advanced Technology Center, 3050 Lomita Boulevard, Torrance, California 90505.

27. E. J. Wall, U.S. Department of Energy, EE-2G/Forrestal Building, 1000 Independence Avenue, S.W., Washington, D.C. 20585.

28. B. Welchko, General Motors Advanced Technology Center, 3050 Lomita Boulevard, Torrance, California 90505.

29. P. G. Yoshida, U.S. Department of Energy, EE-2G/Forrestal Building, 1000 Independence Avenue, S.W., Washington, D.C. 20585. 